The photo-oxidation data are consistent with the presence of some group other than thiol (such as histidine, tryptophan or methionine) at a site concerned with the sequestration of calcium ions by sarcotubular membranes and of such a group in sarcotubular Mg-ATPase activities, these groups perhaps being involved in the binding of the relevant substrates. The $p \mathbf{H}$ dependence of the sarcotubular Mg-ATPase and the marked protective action of imidazole compounds against loss of Mg-ATPase activity and the ability to take up calcium ions during ageing of the sarcotubular fragments strongly suggest but do not rigorously prove that it is the imidazole group which is involved.

This work was supported by grants from the US Public Health Service and the US National Science Foundation.

$$
\begin{aligned}
& \text { B. P. YU } \\
& \text { E. J. Masoro } \\
& \text { F. D. DeMartinis }
\end{aligned}
$$

Department of Physiology and Biophysics,

The Woman's Medical College of Pennsylvania, Philadelphia.

Received August 21; revised October 16, 1967.

${ }^{1}$ Hasselbach, W., and Seraydarian, K., Biochem. Z., 345, 159 (1966).

Seraydarian, K., and Mommaerts, W. F. H. M., J. Cell Biol., 26, 641 (1965)

${ }^{3}$ Fiske, C. H., and Subarrow, Y., J. Biol. Chem., 66, 375 (1929).

4 Carsten, M., and Mommaerts, W. F. H. M., J. Gen. Physiol., 48, 183 (1964).

${ }^{5}$ Martonosi, A., and Ferretos, R., J. Biol. Chem., 239, 648 (1964).

${ }^{6}$ Lowry, O. H., Rosebrough, N. J., Farr, A. L., and Randall, R. J., J. Biol. Chem.,198, 265 (1951).

${ }^{7}$ Barnard, E. A., and Stein, W. D., Adv. in Enzymol., 20, 51 (1958).

${ }^{8}$ Weil, L., and Seibles, T. S., Arch. Biochem. Biophys., 54, 368 (1955).

'Westhead, F. W., Biochemistry, 4, 2139 (1965).

\section{Role of Intestinal Lymphatics in Copper Absorption}

THe immediate appearance of copper-64 in the peripheral blood of rats, rabbits, sheep and men after oral ingestion of the isotope indicates that the upper gastrointestinal tract is an important site for the absorption of copper ${ }^{1-3}$. The role, if any, of the intestinal lymphatics in the absorption mechanism is unknown and has not been reported. In order to elucidate this role, we have compared the relative proportions of absorbed copper which are transported from the intestine by portal blood and by lymph.

Three mongrel dogs, weighing $12-15 \mathrm{~kg}$, were anaesthetized with intravenous pentobarbital. After laparotomy, an 'Intramedic $P E$ 120' polyethylene catheter was passed into the portal vein through a mesenteric vein and was kept patent during the intervals between sampling by means of a slowly dripping solution of 5 per cent dextrose in normal salino containing $10 \mathrm{U}$ of heparin $/ \mathrm{ml}$. A second catheter was inserted into the thoracic duct at its junction with the subclavian vein to collect lymph during the period of the experiment. As soon as lymph was flowing freely, $0.5 \mathrm{mc}$. of copper-64 nitrate containing $600 \mu \mathrm{g}$ of ionic copper was administered in milk to each animal either through a peroral rubber tube into the stomach or by a duodenostomy. In one experiment, the milk mixture was placed just beyond the ligament of Treitz into a $12.5 \mathrm{~cm}$ loop of jejunum isolated by ligatures at both ends. The concentration of copper-64 in plasma and lymph was assayed in a Nuclear-Chicago well-type scintillation detector $D S 202(V)$ and a model 8725 analyser/ scaler. Ono millilitre of portal blood was drawn at intervals of 5-15 min for about $90 \mathrm{~min}$. All the lymph flowing from the thoracic duct was collected during the same intervals. The mean concentrations of copper-64 in plasma and lymph, determined in three experiments, were plotted against time. Figure 1 shows that the copper concentration of lymph rises more slowly than that of portal blood

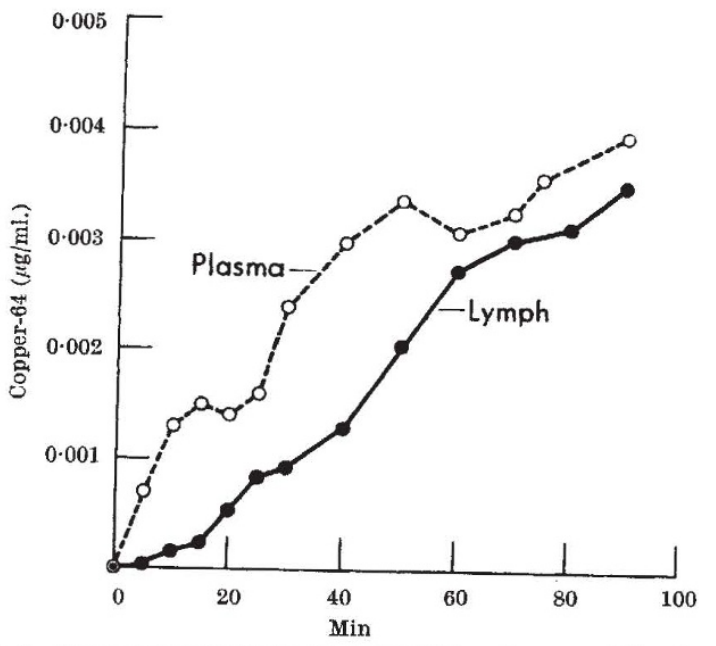

Fig. 1. Mean concentrations of copper-64 in plasma and lymph at various times following administration of copper-64 nitrate to three dogs.

and remains much lower for approximately $l \mathrm{~h}$, after which concentrations of copper in both fluids tend to become equal. Of the $600 \mu \mathrm{g}$ of copper placed in the loop of jejunum which was tied off, $310 \mu \mathrm{g}$ remained in the lumen and intestinal wall after $90 \mathrm{~min}$. Of the $290 \mu \mathrm{g}$ of copper absorbed, only $0.12 \mu \mathrm{g}$ was recovered from the total of $38 \mathrm{ml}$. of lymph collected in this period. The remainder-little less than $290 \mu \mathrm{g}$-clearly had been absorbed through the blood which could not be collected quantitatively.

The quantitative insignificance of lymphatic absorption of copper has also been noted in a study with a man aged 28 suffering from Laënnec's cirrhosis and portal hypertension. Following therapeutic catheterization of the thoracic duct (for decompression of ascites ${ }^{4}$ ) and umbilical vein, the concentraticn of copper-64 given intragastrically in a dose of $1,000 \mu \mathrm{g}$ of copper reached $0.005 \mu \mathrm{g}$ in $192 \mathrm{ml}$. of lymph, collected over $110 \mathrm{~min}$. The concentration of absorbed copper in lymph is lower than that in portal blood (Fig. 1) and the volume of lymph produced in a given time is considerably less than that of portal blood flow ${ }^{4}$, and so the amount of copper absorbed through the lymph is negligible compared with that transported through the blood. Albumin binds almost all copper immediately after absorption ${ }^{5}$ and is present in roughly equal concentrations in lymph and blood 4 , and is there. fore unlikely to account for the difference in copper absorption observed. Amino-acids which are passed into the portal circulation ${ }^{6}$ also bind copper? ${ }^{2}$. This suggests a possible role for these substances in the transport of the metal across the mucosa.

This work was supported in part by research and training grant funds from the US Public Health Service, National Institutes of Health, and from the Life Insurance Medical Research Fund.

\section{Irmin Sternlieb}

Cornelis J. A. Van Den Hamer Seymour Alpert

Dopartments of Medicine and Surgery,

Albert Einstein College of Modicine,

Bronx, New York.

Received August 14; revised Octoher 2, 1967.

2 Owen, C. A., Amer. J. Physiol., 207, 1203 (1964).

2 Van Campen, D. R., and Mitchell, E. A., J. Nutrit., 86, 120 (1965).

a Sternlieb, I., Gastroenterology, 52, 1038 (1967).

${ }^{4}$ Dumont, A. F., and Mulholland, J. H., in Progress in Liver Diseases, 2. 427 (Grune and Stratton, 1965).

${ }^{5}$ Bearn, A. G., and Kunkel, H. G., Proc. Soc. Exp. Biol. and Med., 84, 44 (1954).

- Sheehy, T. W., and Floch, M. H., in The Small Intestine, 86 (Harper and Row, 1964).

' Neumann, P. Z., and Sass-Kortsak, A., J. Clin. Inøset., 46, 646 (1967). 